\title{
What does the clinician need to improve patient care in systemic sclerosis?
}

\section{Madelon C Vonk, Frank H J van den Hoogen, Piet L C M van Riel, Gabriele Valentini}

\section{Validated clinimetric criteria, useful in the early phase of systemic sclerosis, are lacking}

S ystemic sclerosis (SSc) is a multisystemic disorder of unknown cause characterised by fibrotic and degenerative changes in skin, blood vessels and internal organs. ${ }^{1}$ The clinical spectrum of SSc, and hence its prognosis, is quite variable. ${ }^{2}$ Validated subset classification, activity and severity criteria are available..$^{2-7}$ However, despite their usefulness, these criteria have several limitations. Furthermore, diagnostic criteria of SSC are lacking. To improve the care of patients with scleroderma, the clinician needs to initiate optimal, early treatment. Diagnostic criteria that aid early diagnosis as well as classification, severity criteria that aid estimation of prognosis, and disease activity criteria that indicate active disease could help the clinician in daily practice. Present international collaborations such as the EULAR Scleroderma Trial and Research Group (EUSTAR) and the North American Scleroderma Clinical Trials Consortium (SCTC) are thriving, providing the ideal circumstances for clinimetric studies of SSc.

This editorial discusses the state of the art of clinimetrics in SSc and possible ways to overcome the present limitations.

\section{DIAGNOSTIC CRITERIA}

Diagnostic criteria, especially for the early phase, are indispensable for estimation of prognosis and for timely initiation of treatment. The American College of Rheumatology (ACR) Preliminary Criteria for the Classification of Systemic Sclerosis (Scleroderma), developed in 1980, are often used to diagnose patients with SSc. ${ }^{3}$ The objective of these classification criteria was to establish a standard for definite or certain disease in order to permit comparison of groups of patients from different centres and to assist in proper evaluation of the results of clinical and therapeutic trials and not to aid the diagnosis of early SSc in the individual patient. $^{3}$ These preliminary criteria were established in a prospective multicentre study in which adult patients with scleroderma were included who were diagnosed within 2 years of study entry. Patients were subgrouped into three categories: definite, probable or early stage, and overlap syndrome. In total, 264 patients with definite SSc were included, and their characteristics were compared with those of 413 patients with systemic lupus erythematosus, polymyositis/dermatomyositis or Raynaud's phenomenon not associated with the previously mentioned disorders.

The preliminary ACR classification criteria are not suitable for the early and correct diagnosis of SSC for several reasons. First of all, the absence in the control group of scleroderma-like diseases usually seen by dermatologists resulted in patients with eosinophilic fasciitis, diffuse morphoea or other related conditions also fulfilling the preliminary ACR criteria. Secondly, the patients with SSc who were selected for the study were probably "classic" cases, and patients with less well differentiated, early disease were less likely to be included. Indeed a significant percentage of patients with limited cutaneous disease do not fulfil the preliminary ACR criteria. $^{28}$ Furthermore, disease-specific autoantibodies such as anti-topoisomeras 1 and anti-centromere, which are highly specific for SSc, may be of importance in the diagnosis of SSc and were not taken into account. The same holds true for application of wide-field nailfold capillaroscopy. ${ }^{9}$ Finally, following the suggestions of LeRoy and Medsger, ${ }^{10}$ data have been provided that support the diagnosis of SSc in an early "prescleroderma" stage in cases where there is no skin thickening, referred to as "limited" SSc. Uniformly applicable diagnostic criteria of SSc require that these are developed in patients with early SSc, and not in patients with established disease.

\section{SUBSET CLASSIFICATION CRITERIA}

Subset classification criteria are intended to identify and separate disease subsets in which the natural history and prognoses may vary. The variability in the clinical and prognostic features of the disease has long prompted investigators to subdivide SSc into distinct, mutually exclusive subsets. At present, the most widely used subsetting scheme differentiates two clinical subsets-limited and diffuse cutaneous forms - which can be distinguished by the extent of skin involvement, their autoantibody profile, and the pattern of organ involvement. In limited cutaneous SSc, skin involvement is present distal from the elbows and knees, usually with involvement of the face, whereas in diffuse cutaneous SSc, skin involvement is also present more proximally. ${ }^{2}$ The major disadvantage of this subset classification model is that patients with early disease, without or with minimal skin changes and no internal organ involvement, do not fit. The amended 2001 criteria of Le Roy and Medsger ${ }^{10}$ include the presence of Raynaud's phenomenon, nailfold capillaroscopic changes, and disease-specific autoantibodies, resulting in a "prescleroderma" or limited SSc subset, allowing patients with early disease to be classified. However, this model has not been validated to date. Another scheme differentiates three subsets: limited, intermediate and diffuse cutaneous disease. In this scheme are represented the limited cutaneous subset of patients with skin involvement confined to digits with or without involvement of the face, the intermediate cutaneous subset with skin involvement of the limbs, and the diffuse cutaneous subset with skin involvement of the trunk. ${ }^{11}{ }^{12}$ It has been shown that this model has greater discriminant power with regard to survival than the two-subset model. ${ }^{11}$ As pathological alterations and clinical manifestations of SSc are a continuum, any subsetting model involving only the extent of skin changes seems arbitrary and restrictive. ${ }^{12}$ Therefore, subsetting classification criteria that include the disease-specific autoantibodies and additional imaging such as nailfold capillaroscopy, validated in a cohort of patients with scleroderma and also with early disease, may aid the development of an optimal classification model.

\section{ACTIVITY CRITERIA}

A measure of activity reflects the ongoing disease process and ideally forecasts damage and thus indicates when intervention is needed, whereas a measure of damage reflects the extent of organ dysfunction. ${ }^{13}$ The OMERACT collaboration provides validated outcome measurements that are available for assessment of activity and damage. ${ }^{14}$

In 1995, the European Scleroderma Study Group (EScSG) initiated a multicentre prospective study to define disease 


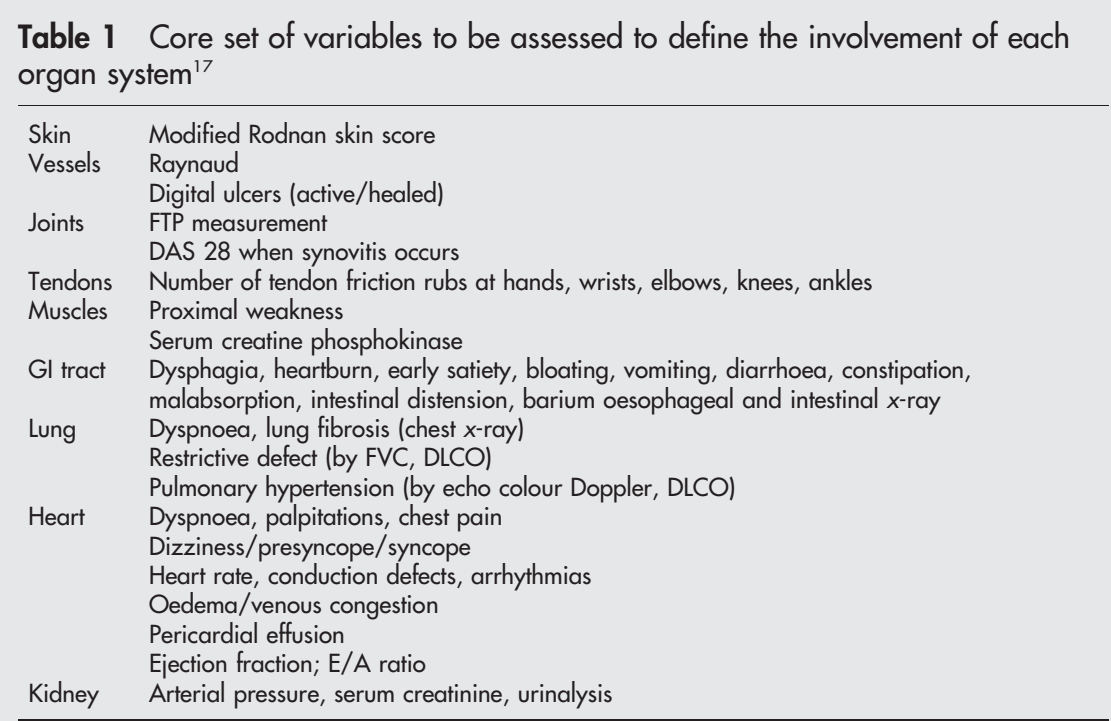

DLCO, carbon dioxide diffusion lung capacity; FTP, finger tip distance; FVC, forced vital capacity; GI, gastrointestinal.

and prognostic value of this scale has not yet been tested.

\section{FUTURE RESEARCH IN CLINIMETRICS}

SSc still lacks validated clinimetric criteria that are clinically useful in the very early phase of the disease process. To improve patient care, validated criteria for diagnosis, prognosis, disease activity and severity are essential. Most importantly, these criteria and instruments should be developed and validated in the population of interest: patients with SSc at a very early phase of the disease process.

\section{ACKNOWLEDGEMENTS}

We thank Dr J Fransen for greatly appreciated discussions, and Mrs A I Smetsers, MA, for technical support.

Ann Rheum Dis 2007;66:1129-1131.

doi: 10.1136/ard.2007.073957

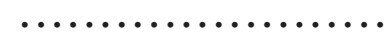

\section{Authors' affiliations}

Madelon C Vonk, Piet L C M van Riel, Department of Rheumatology, Radboud University Nijmegen Medical Centre, Nijmegen, the Netherlands

Frank H J van den Hoogen, St Maartenskliniek, Niimegen, the Netherlands

Gabriele Valentini, Seconda Universita degli

Studi di Napoli, Napoli, Italy

\section{DAMAGE/SEVERITY SCALE}

developed criteria for disease activity SSc. ${ }^{6}$ Unfortunately, the results of this study were flawed by a high number of missing values, especially in the investigations on disease activity in internal organs, which were consequently ruled out. Further, there were three "change" items in the final scale. These change items consisted of an evaluation by the patients of symptoms caused by organ dysfunction compared with the previous month. However, the disease may have been active in the previous month and those change items are therefore not necessarily a reflection of actual disease activity. The change items are actually response measurements and therefore should not be included in an activity score. Also, the patients with scleroderma included in the study had a wide range of disease duration, and their symptoms may have been caused by damage. To avoid confounding between damage and disease activity, the activity criteria must be assessed in patients with scleroderma with early disease. The study of construct validity of this score was successful, but showed that even among experts there is a low level of agreement in the assessment of disease activity. ${ }^{16}$ The criteria were externally validated, and, in a consensus conference of the EScSG in 2002, the components of the criteria were chosen as the variables for the assessment of disease activity in SSc. ${ }^{7}$ At the same conference, a core set of variables that
A disease severity scale is useful in assessing disease status, both at a given point in time and during evolution over time, and may aid evaluation of treatment effects and establishment of the prognosis in the individual patient. From 1976 onwards, different investigators developed a disease severity scale for SSc, but those scales were not validated. In 1999, Medsger et $a l^{4}$ proposed and validated severity criteria for SSc. Experts from different centres identified nine organ systems and chose variables to assess these organ functions depending on the overall availability and the importance in the doctor's judgement. The involvement of each organ system was graded from 0 (no documented involvement) to 4 (end stage disease). The proposed scale was prospectively tested in 78 newly referred patients, and the variables were adapted according to the results of this study and subsequently externally validated. Finally, the severity criteria were discussed by experts to ensure face and content validity as well as consensus. ${ }^{4}$ Drawbacks of the severity scale, as pointed out by the authors themselves, include the lack of a weighting system discriminating more severely ill patients from those with a more extensive but indolent disease. The severity scale was modified, resulting in the revised preliminary SSc severity scale in 2002. ${ }^{5}$ However, the sensitivity to change
Correspondence to: Dr M C Vonk, Department of Rheumatology, Radboud University Nijmegen Medical Centre, PO Box 9101, $6500 \mathrm{HB}$ Nijmegen, the Netherlands; M.Vonk@reuma. umcn.nl

\section{Accepted 15 June 2007}

Competing interests: None.

\section{REFERENCES}

1 Furst DE, Clements PJ. Hypothesis for the 1997;24:53-7.

2 Leroy EC, Black C, Fleischmajer R, Jablonska S, Krieg T, Medsger TA, et al. Scleroderma (systemic sclerosis): classification, subsets and pathogenesis. J Rheumatol 1988;15:202-5.

3 Subcommittee for Scleroderma Criteria of the American Rheumatism Association diagnostic and therapeutic committee. Preliminary Criteria for the Classification of Systemic-Sclerosis (Scleroderma). Arthritis Rheum 1980;23:581-90.

4 Medsger TA, Silman AJ, Steen VD, Black CM, Akesson A, Bacon PA, et al. A disease severity scale for systemic sclerosis: development and testing. J Rheumatol 1999;26:2159-67.

5 Medsger TA, Bombardieri S, Czirjak L, Scorza R, Della Rossa A, Bencivelli W. Assessment of disease severity and prognosis. Clin Exp Rheumatol 2003;21:S42-6.

6 Valentini G, Della Rossa A, Bombardieri S, Bencivelli W, Silman AJ, D'Angelo S, et al. European multicentre study to define disease activity criteria for systemic sclerosis. II. Identification of disease activity variables and development of preliminary activity indexes. Ann Rheum Dis 2001;60:592-8.

7 Valentini G, Silman AJ, Veale D. Assessment of disease activity. Clin Exp Rheumatol 2003;21:S39-41. pathogenesis of systemic sclerosis. J Rheumatol 
8 Lonzetti LS, Joyal F, Raynauld JP, Roussin A Goulet JR, Rich E, et al. Updating the American College of Rheumatology preliminary classification criteria for systemic sclerosis: addition of severe nailfold capillaroscopy abnormalities markedly increases the sensitivity for limited scleroderma Arthritis Rheum 2001;44:735-6.

9 Scussel-Lonzetti L, Joyal F, Raynauld JP, Roussin A, Rich E, Goulet JR, et al. Predicting mortality in systemic sclerosis: analysis of a cohort of 309 French Canadian patients with emphasis on features at diagnosis as predictive factors for survival. Medicine 2002;81:154-67.

10 Leroy EC, Medsger TA. Criteria for the classification of early systemic sclerosis. J Rheumatol 2001;28:1573-6.
11 Barnett AJ, Miller MH, Littlejohn GO. A survival study of patients with scleroderma diagnosed over 30 years (1953-1983): the value of a simple cutaneous classification in the early stages of the disease. J Rheumatol 1988;15:276-83.

12 Valentini G, Ferri C. Scleroderma subsetting. Curr Rheumatol Rev 2006;2:83-7.

13 Clements PJ. Measuring disease activity and severity in scleroderma. Curr Opin Rheumato 1995; 7:517-21.

14 Furst D, Khanna D, Matucci-Cerinic M, Clements $P$, Steen V, Pope J, et al. Systemic sclerosis: continuing progress in developing clinical measures of response. J Rheumatol 2007;34:1194-200.

15 Della Rossa A, Valentini G, Bombardieri S Bencivelli W, Silman AJ, D'Angelo S, et al.
European multicentre study to define disease activity criteria for systemic sclerosis. I. Clinical and epidemiological features of 290 patients from 19 centres. Ann Rheum Dis 2001;60:585-91.

16 Valentini G, Bencivelli W, Bombardieri S D'Angelo S, Della Rossa A, Silman AJ, et al. European Scleroderma Study Group to define disease activity criteria for systemic sclerosis. III. Assessment of the construct validity of the preliminary activity criteria. Ann Rheum Dis 2003;62:901-3.

17 Valentini G, Medsger TA, Silman AJ Bombardieri S. Conclusion and identification of the core set of variables to be used in clinical investigations. Clin Exp Rheumatol 2003;21:S47-8.

\section{BMJ Clinical Evidence-Call for contributors}

BMJ Clinical Evidence is a continuously updated evidence-based journal available worldwide on the internet which publishes commissioned systematic reviews. BMJ Clinical Evidence needs to recruit new contributors. Contributors are healthcare professionals or epidemiologists with experience in evidence-based medicine, with the ability to write in a concise and structured way and relevant clinical expertise.

Areas for which we are currently seeking contributors:

- Secondary prevention of ischaemic cardiac events

- Acute myocardial infarction

- MRSA (treatment)

- Bacterial conjunctivitis

However, we are always looking for contributors, so do not let this list discourage you.

Being a contributor involves:

- Selecting from a validated, screened search (performed by in-house Information Specialists) valid studies for inclusion.

- Documenting your decisions about which studies to include on an inclusion and exclusion form, which we will publish.

- Writing the text to a highly structured template (about 1500-3000 words), using evidence from the final studies chosen, within 8-10 weeks of receiving the literature search.

- Working with BMJ Clinical Evidence editors to ensure that the final text meets quality and style standards.

- Updating the text every 12 months using any new, sound evidence that becomes available. The BMJ Clinical Evidence in-house team will conduct the searches for contributors; your task is to filter out high quality studies and incorporate them into the existing text.

- To expand the review to include a new question about once every 12 months.

In return, contributors will see their work published in a highly-rewarded peer-reviewed international medical journal. They also receive a small honorarium for their efforts.

If you would like to become a contributor for BMJ Clinical Evidence or require more information about what this involves please send your contact details and a copy of your CV, clearly stating the clinical area you are interested in, to CECommissioning@bmigroup.com.

\section{Call for peer reviewers}

BMJ Clinical Evidence also needs to recruit new peer reviewers specifically with an interest in the clinical areas stated above, and also others related to general practice. Peer reviewers are healthcare professionals or epidemiologists with experience in evidence-based medicine. As a peer reviewer you would be asked for your views on the clinical relevance, validity and accessibility of specific reviews within the journal, and their usefulness to the intended audience (international generalists and healthcare professionals, possibly with limited statistical knowledge). Reviews are usually 1500-3000 words in length and we would ask you to review between 2-5 systematic reviews per year. The peer review process takes place throughout the year, and our turnaround time for each review is 10-14 days. In return peer reviewers receive free access to BMJ Clinical Evidence for 3 months for each review.

If you are interested in becoming a peer reviewer for BMJ Clinical Evidence, please complete the peer review questionnaire at www.clinicalevidence.com/ceweb/contribute/peerreviewer.jsp 